\title{
The value of diffusion-weighted imaging in assessing the ADC changes of tissues adjacent to breast carcinoma Zhang Yili*1, Huang Xiaoyan ${ }^{1}$, Du Hongwen ${ }^{1}$, Zhang Yun ${ }^{1}$, Chen Xin², Wang Peng 2 and Guo Youmin ${ }^{3}$
}

Address: ${ }^{1}$ Imaging center, the 1st Affiliated Hospital of Medical College, Xi'an Jiaotong University, Xi'an 710061, PR China, ${ }^{2}$ Imaging center, the 2nd Affiliated Hospital of Medical College, Xi'an Jiaotong University, Xi'an 710004, PR China and ${ }^{3}$ Department of Radiology of Beijing ChaoYang Hospital, Captial Medical University, Beijing 100020, PR China

Email: Zhang Yili* - yilishengli@hotmail.com; Huang Xiaoyan - hxyfisher@163.com; Du Hongwen - dwendy@126.com; Zhang Yun - imagingzhang@126.com; Chen Xin - chen_x129@163.com; Wang Peng - yt.wangpeng813@163.com;

Guo Youmin - cjr.guoyoumin@vip.163.com

* Corresponding author

Published: 14 January 2009

BMC Cancer 2009, 9:18 doi:10.1/86/1471-2407-9-18
Received: II January 2008

Accepted: 14 January 2009

This article is available from: http://www.biomedcentral.com/I47/-2407/9//8

(c) 2009 Yili et al; licensee BioMed Central Ltd.

This is an Open Access article distributed under the terms of the Creative Commons Attribution License (http://creativecommons.org/licenses/by/2.0), which permits unrestricted use, distribution, and reproduction in any medium, provided the original work is properly cited.

\begin{abstract}
Background: To define a threshold value of apparent diffusion coefficient (ADC) with which malignant breast lesions can be distinguished from benign lesions, and to evaluate the $A D C$ change of peri-tumor tissue in breast carcinoma by echo planar-diffusion weighted imaging (EPI-DWI).

Methods: 57 breast lesions were scanned by routine MRI and EPI-DWI. The ADC values were compared between malignant and benign lesions. The sensitivity and specificity of EPI-DWI and the threshold ADC value were evaluated by Receiver Operating Characteristic curve (ROC). The $A D C$ values of malignant lesion and layered peri-tumor tissues (from innermost layer $I$ to outermost layer 4 with $5 \mathrm{~mm}$ every layer) in different directions were compared and the ADC values among different layers were compared.
\end{abstract}

Results: The ADC value of 35 malignant lesions was statistically lower than that of 22 benign lesions $(P<0.05)$. In ROC curve, the threshold value was $1.24+/-0.25 * 10 E-3 \mathrm{~mm}^{2} / \mathrm{s}(b=500)$ or $1.20+/-0.25 * 10 \mathrm{E}-3 \mathrm{~mm}^{2} / \mathrm{s}(\mathrm{b}=1000)$. The ADC value of malignant lesions was statistically lower than that of peri-tumor tissues in different directions $(P<0.05)$. For peri-tumor tissues, the ADC values increased gradually from layer I to layer 4 and there was a significant difference between the ADC values of layer I and layer $2(P<0.05)$; while from layer 2 outwards, there was no statistical difference among different layers.

Conclusion: ADC value was a sensitive and specific parameter that could help to differentiate benign and malignant breast lesions. ADC changes in tissues adjacent to breast carcinoma could be detected by EPI-DWI, which made EPI-DWI a promising method for helping to determine surgical scope of breast carcinoma. 


\section{Background}

Conservative surgery has become a well-established alternative to mastectomy in the treatment of breast cancer. However, in case of larger lesions or small-size breasts, the removal of adequate volumes of breast tissue to achieve tumor-free margins and reduce the risk of local relapse may compromise the cosmetic outcome, causing unpleasant results [1]. An issue of critical importance is thus to know well the transition from the tumor tissue to normal tissue in breast carcinoma in order to helpfully decide the surgical scope. Currently, the evaluation of tumor scope in clinical works relies on pathologic examination of margins free of gross tumor tissues. However, previous studies reported that in some patients with histologically negative margins, a relatively high recurrence rate was still observed [2]. It was thought that genetic and molecular alteration precedes phenotypic changes, therefore histologic assessment alone may be inadequate to detect the presence of transformed cells in surgical margins [3]. In another word, histologic assessment alone may be insufficient for the detection of transition from the tumor tissue to normal tissue. A recent study [4] discovered that there existed the geographic zones of the normal tissue adjacent to invasive cancers in which methylation changes could be identified and the authors summarized that multiple gene promoters could be used as a surrogate biomarker to define the molecular margin of lumpectomy in the future. Studies of other malignant lesions [3,5-9], including head and neck cancer, pancreatic cancer, lung cancer, colorectal carcinoma, rectal cancer and hepatocellular carcinoma, also demonstrated that there existed a molecular border of tumor tissues with various molecular methods. However, all of these studies were performed on the biopsy tissues or resected tissue specimens and no preoperative assessment of peri-tumor was reported. There is, therefore, a need for a non-invasive technique to detect the change of peri-tumor tissue for the purpose of providing more information about surgical scope.

Magnetic resonance imaging (MRI) has a high resolution and can provide much more detailed images than mammography and ultrasonography (US), which makes it a widely-used tool for the diagnosis of breast lesions. However, the conventional breast MRI (plain MRI) is still a morphological diagnostic technique which only provides general anatomical information such as signal, shape, size and location. One of the latest advancements in MRI technology is the application of diffusion-weighted imaging (DWI). The principle underlying DWI is that the thermal motion of water molecules in extracellular fluid enables the acquisition of images that reflect both histological structure and cellularity [10] and therefore it can detect the changes of tissue structure at molecular level. It also enables the quantitative evaluation of apparent diffusion coefficient (ADC), which may be useful for distinguishing malignant from benign tissues and monitoring therapeutic outcome $[11,12]$. Compared with benign lesions, diffusion of malignant tumors with high cellular tissue decreased and the ADC value in malignant tumors is lower than that of benign lesions [13-15]. Several latest studies have shown that ADC has a potential for clinical appreciation in differentiating benign and malignant lesions with good specificity [16-19].

On the other side, DWI, based on its imaging mechanism, could detect the changes of ADC in different tissues. Measurement of the ADC provides a quantitative estimate of the restrictive nature of the motion of water molecules within tissue for each voxel in a diffusion-weighted image. This study was thus designed to compare the ADC values between malignant and benign lesions in breast and to study the change of ADC values in peri-tumor tissues through echo planar diffusion weighted imaging (EPIDWI). Our main aim was to study the DWI changes in tissues adjacent to breast carcinoma, which would be helpful for the clinical surgeon to decide the scope and pattern of operation.

\section{Methods}

This study was approved by the ethics committee of Xi'an Jiaotong University and all patients gave written informed consent before beginning the study.

\section{Patients}

54 cases with 57 breast lesions were examined by ultrasound and/or mammography before MRI from June 2006 to January 2007 in our hospital. No previous chemotherapy or radiotherapy or surgery was administrated to these patients. All patients were female and aged between 31 and 77 years (mean age: 46.3 years). All patients underwent surgical resection and received definite pathological diagnosis in our hospital.

\section{Histological details}

Findings were 22 benign lesions in 21 cases, including 14 breast fibroadenoma and 8 breast hyperplasia. Malignant lesions totalled 35 in 33 patients, including 31 infiltrating ductal carcinoma (IDC), 3 ductal carcinoma in situ (DCIS) and 1 breast malignant phyllode. Lymph nodes metastasis in malignant lesions was observed in 13 cases. The mean of largest diameter of the benign lesions was $38.0 \mathrm{~mm}$ (from 8 to $106 \mathrm{~mm}$ ) and that of breast cancer was $28.4 \mathrm{~mm}$ (from 10 to $55 \mathrm{~mm}$ ) and the largest diameter of 1 breast malignant phyllode was $72.4 \mathrm{~mm}$.

\section{MRI protocols and imaging}

MRI was performed with a $1.5 \mathrm{~T}$ MR system (Philips, Gyroscan NT Release6, Netherlands) and a dedicated phased-array bilateral breast coil, with the patient lying prone and the breast in a holder to reduce motion. The 
imaging protocols included a sagittal T1-weighted (T1-W) water selective excitation (WATS) first field echo (FFE) pulse sequence $\left(\right.$ matrix $=512^{2}$, slice thickness $=5 \mathrm{~mm}$, Flip angle (deg) = 25.00); a T2-weighted transverse (T2-W) turbo spin-echo (TSE) pulse sequence (matrix $=512^{2}$, slice thickness $=5 \mathrm{~mm}$, Flip angle $(\mathrm{deg})=90.00)$; and an Gradient echo planar image (EPI) DWI pulse sequence $($ matrix $=128, \mathrm{FOV}(\mathrm{mm})=350.00$, slice thickness $=5$ $\mathrm{mm}$, Flip angle $(\mathrm{deg})=90.00$, diffusion mode $=\mathrm{SE}, \mathrm{NSA}=$ 1). We modified $b$-values ( $b=500$ second $/ \mathrm{mm}^{2}$ and 1000 second $/ \mathrm{mm}^{2}$ ) to assume a better-fit convergence. Finally we obtained two trace-weighted images and ADC maps reconstruction. The analysis of magnetic resonance images of the 57 lesions was shown in Table 1 (Figure 1, 2).

\section{ADC value}

All ADC values were calculated according to the formula: $\mathrm{ADC}=-(1 / \mathrm{b}) \operatorname{In}(\mathrm{S} / \mathrm{So})$, where So and $\mathrm{S}$ are the signal intensities in the region of interest (ROI), obtained with different gradient factors (b values of 500, and $1000 \mathrm{sec}$ ond $/ \mathrm{mm}^{2}$ ). ADC distribution was demonstrated on an ADC map created with Easy Vision Workstation (Philips, Netherlands). The ROI was placed in and around the tar-
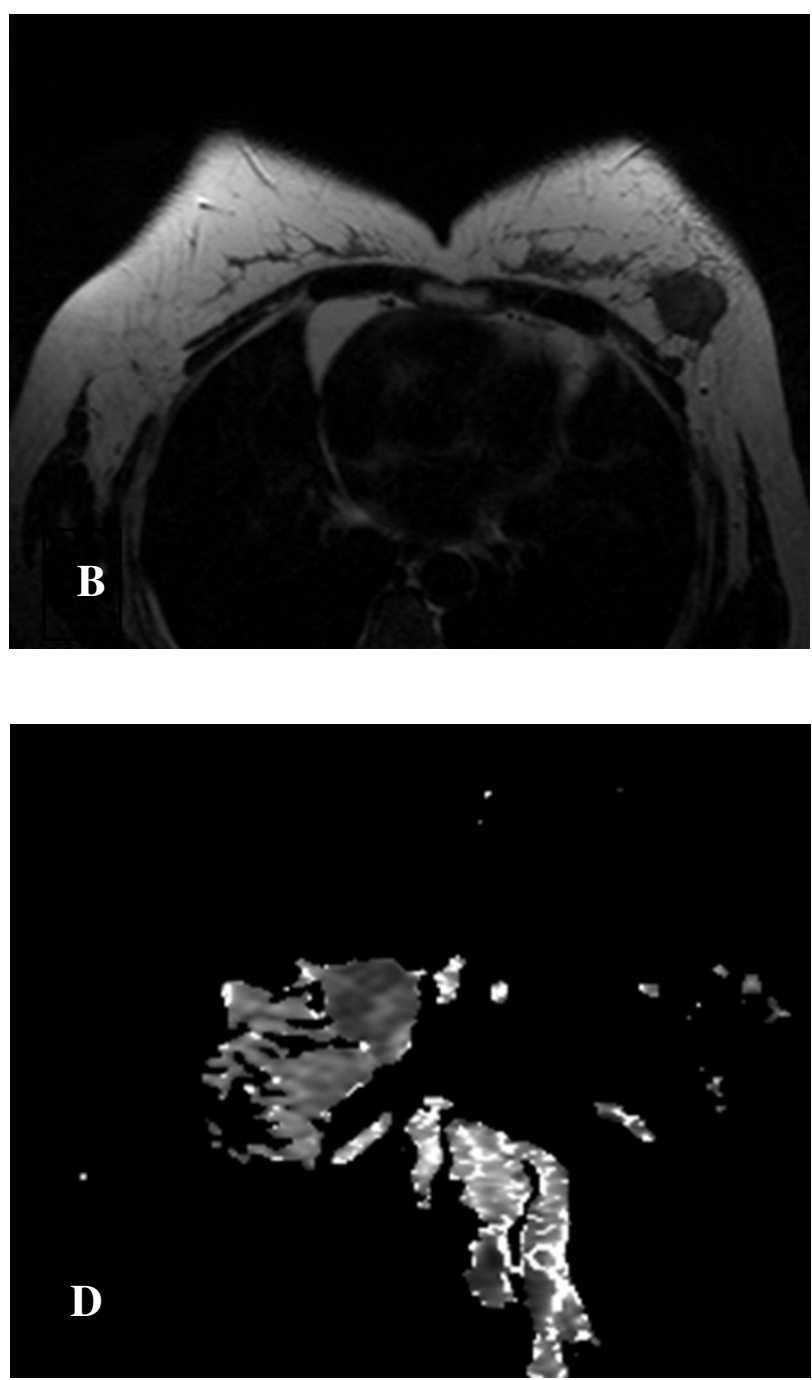

\section{Figure I}

45-year-old woman with IDC in the left breast. A: WATS TI-weighted sagittal scan showed irregularly mass in the left breast with hyperintense signal. B: T2-weighted transverse scan showed the lesion was hypointense with spicule sign. C: EPIDWI sagittal scan showed lesion with slightly inhomogeneity hyperintense in DWI. D: Inhomogeneity hypointense was found in $\operatorname{ADC}$ map $(b=500)$ and the ADC was $0.94 \pm 0.19 \pm 10^{-3} \mathrm{~mm}^{2} / \mathrm{s}$. 

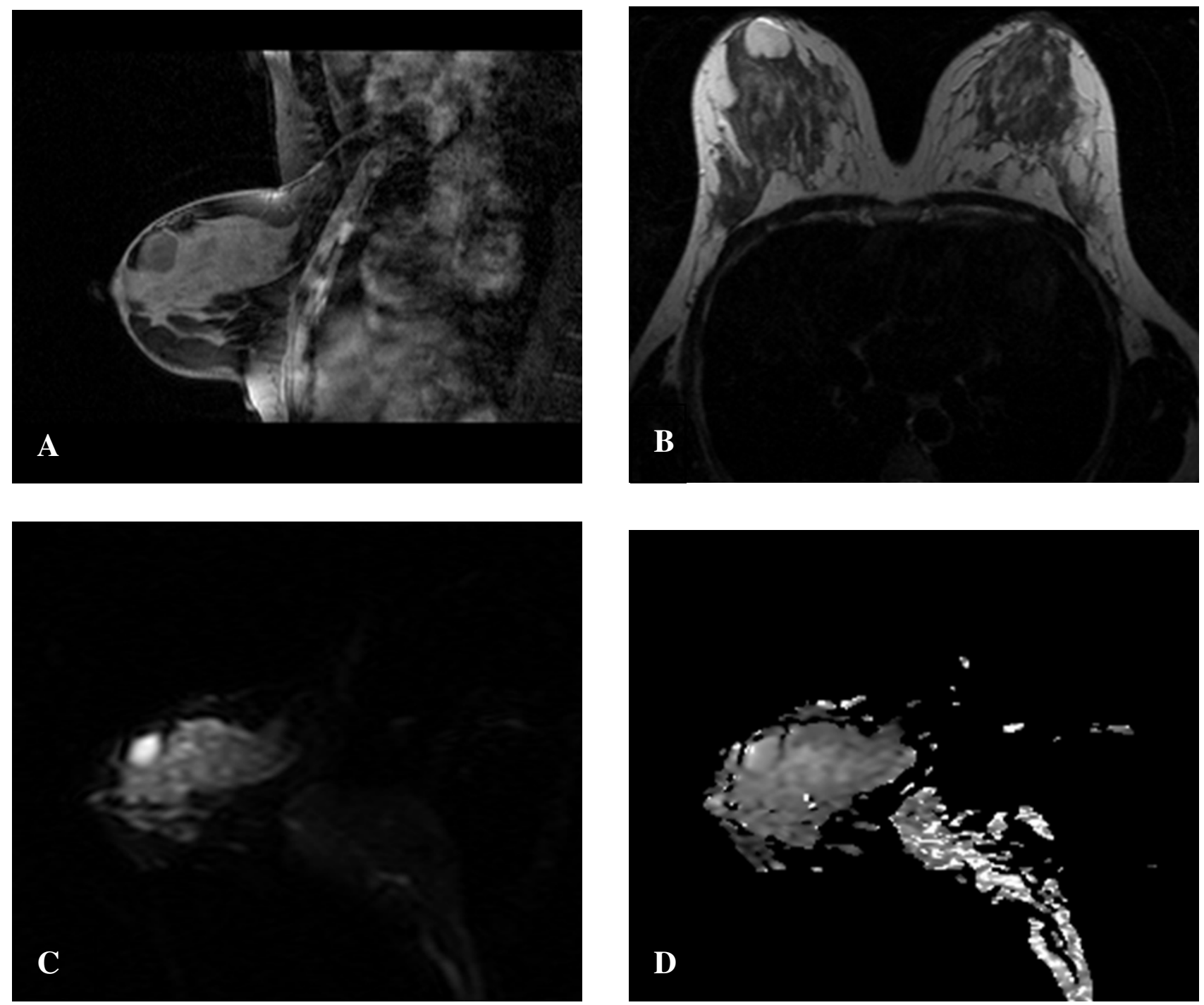

\section{Figure 2}

36-year-old woman with fibroadenoma in right breast. A: WATS TI-weighted sagittal scan showed a regular round slightly hypointense lesion. B: T2-weighted transverse scan showed a round and smooth hyperintense lesion in the right breast. C: EPI-DWI sagittal scan showed a hyperintense lesion in DWI. D: The isointense lesion was in ADC map $(b=1000)$ and the ADC was $2.44 \pm 0.362 \times 10^{-3} \mathrm{~mm}^{2} / \mathrm{s}$.

get lesion and the size of ROI in the lesion was $5 \mathrm{~mm}$ in diameter. The protocol in measuring ADC values by two readers was technologically same.

\section{Statistical analysis}

The Independent-Sample T-test and One-Way ANOVA were used to determine statistical significance. $P$ value $<$ 0.05 was regarded as statistically significant. All above statistical analyses were performed using the SPSS11.5 software package (SPSS Inc, Chicago, IL, USA). Cut-off values between benign and malignant lesions were defined using Receiver Operating Characteristic (ROC) curves.

\section{Results}

Comparison of ADC values between malignant lesions and benign lesions

Either $b=500$ or $b=1000$, the ADC values from reader 1 and reader 2 were highly consistent in all breast lesions: for malignant lesions, when $\mathrm{b}=500, P=0.985$ and when $\mathrm{b}=1000, P=0.890$; while for benign lesions, when $\mathrm{b}=$ 500, $P=0.839$, and when $\mathrm{b}=1000, P=0.764$. (all $P>$ 
Table I: Analysis of magnetic resonance images of the 57 lesions

\begin{tabular}{|c|c|c|c|c|c|}
\hline Classification & No. & WATS TI-weighted & T2-weighted SE & EPI-DWI & ADC map \\
\hline Malignant lesions & 35 & & & & \\
\hline \multirow[t]{2}{*}{ Breast cancer } & 33 & Slightly hyperintense & Hypointense & $\begin{array}{l}\text { Slightly inhomogeneity } \\
\text { hyperintense }\end{array}$ & Inhomogeneity hypointense \\
\hline & 1 & Isointense & Isointense & Hyperintense & Hyperintense \\
\hline Breast sarcoma & 1 & Slightly hypointense & Inhomogeneity hyperintense & $\begin{array}{l}\text { Slightly inhomogeneity } \\
\text { hyperintense }\end{array}$ & $\begin{array}{l}\text { Slightly inhomogeneity } \\
\text { isointense }\end{array}$ \\
\hline Benign lesion & 22 & & & & \\
\hline \multirow[t]{3}{*}{ Fibroadenoma } & 3 & Homogeneity hypointense & Homogeneity hyperintense & Homogeneity hyperintense & Homogeneity hyperintense \\
\hline & 8 & Homogeneity isointense & $\begin{array}{l}\text { Hypointense (2) } \\
\text { Isointense (4) } \\
\text { Hyperintense (2) }\end{array}$ & $\begin{array}{l}\text { Hyperintense (7) } \\
\text { Isointense (I) }\end{array}$ & Isointense \\
\hline & 3 & Homogeneity hyperintense & Hypointense & $\begin{array}{l}\text { Hyperintense (2) } \\
\text { Hypointense (1) }\end{array}$ & $\begin{array}{l}\text { Isointense }(2) \\
\text { Inhomogeneity Hyperintense } \\
\text { (I) }\end{array}$ \\
\hline Breast hyperplasia & 8 & $\begin{array}{l}\text { Densification of gland (6) } \\
\text { Hypointense (I) } \\
\text { Isointense (I) }\end{array}$ & Hyperintense (2) & Hyperintense (2) & $\begin{array}{l}\text { Hyperintense (I) } \\
\text { Hypointense (I) }\end{array}$ \\
\hline
\end{tabular}

0.05) (Table 2). Furthermore, there was no statistical difference between $\mathrm{b}=500$ and $\mathrm{b}=1000$ in malignant lesions or benign lesions (both $P>0.05$ ).

All data were entered into a spreadsheet and ROC methodology was then used to decide the ADC value threshold which could differentiate malignant lesions from benign lesions. ROC curves from both readers were represented in Figure. $3 \mathrm{~A}$ and $3 \mathrm{~B}$. The threshold values of ADC were $1.24 \pm 0.25 \pm 10^{-3} \mathrm{~mm}^{2} / \mathrm{s}(\mathrm{b}=500)$ and $1.20 \pm 0.25 \pm 10^{-}$ ${ }^{3} \mathrm{~mm}^{2} / \mathrm{s} \quad(\mathrm{b}=1000)$, respectively, and the summary of ROC curves about their corresponding sensitivity and specificity were presented in table 3 .

However, the ADC values of malignant lesions and benign lesions were statistically different (both $P<0.001$ for $\mathrm{b}=500$ and $\mathrm{b}=1000$, Table 4 ), which is obviously higher in benign lesions than that in breast malignant lesions, except for one malignant phyllode, whose ADC value was very close to that of benign lesions.

\section{$A D C$ values among different layers and different directions around malignant lesions}

Both readers further evaluated the ADC values of different layers in different directions around the lesions (Figure 4). Since the ADC map in our study was based on a sagittal imaging, only one ADC map with the biggest diameter of tumor was selected and the center of tumor was set as the point to define the upper and lower in vertical direction as well as anterior and posterior in horizontal direction and the ROI distribution was symmetric in opposite directions. Since slice thickness of all above sequences was 5

Table 2: Average ADC values $\left(\times 10^{-3} \mathrm{~mm}^{2} / \mathrm{s}\right)$ measured by reader I and reader 2

\begin{tabular}{|c|c|c|c|c|}
\hline & \multicolumn{2}{|c|}{ Reader I } & \multicolumn{2}{|c|}{ Reader2 } \\
\hline & $b=500$ & $b=1000$ & $b=500$ & $b=1000$ \\
\hline Malignant lesions & $1.04 \pm 0.24^{a}$ & $1.01 \pm 0.19 b$ & $1.04 \pm 0.21$ & $1.01 \pm 0.22$ \\
\hline Benign lesions & $\mathrm{I} .78 \pm 0.3 \mathrm{I}^{\mathrm{c}}$ & $1.72 \pm 0.36^{d}$ & $1.79 \pm 0.28$ & $1.75 \pm 0.33$ \\
\hline
\end{tabular}

aP $=0.985$, vs reader $2 ; \mathrm{b} P=0.890$, vs reader $2 ; \mathrm{c} P=0.839$, vs reader $2 ; \mathrm{d} P=0.764$, vs reader 2. 
ROC Curve

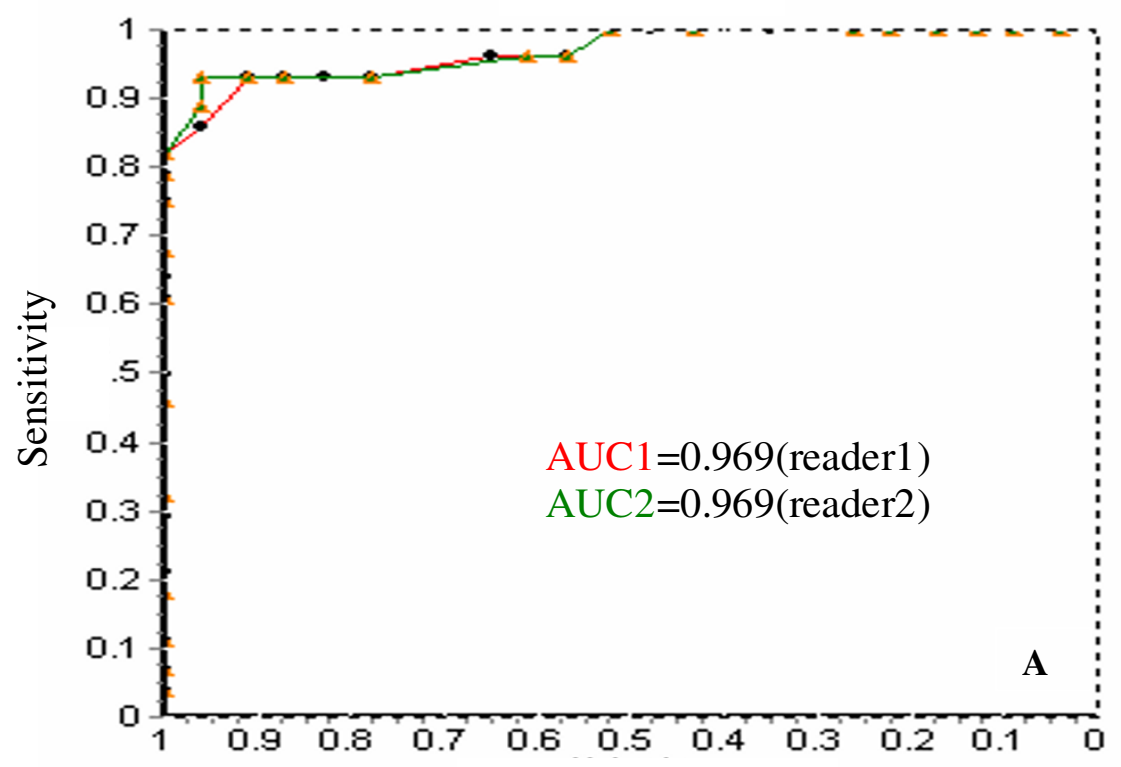

Specificity

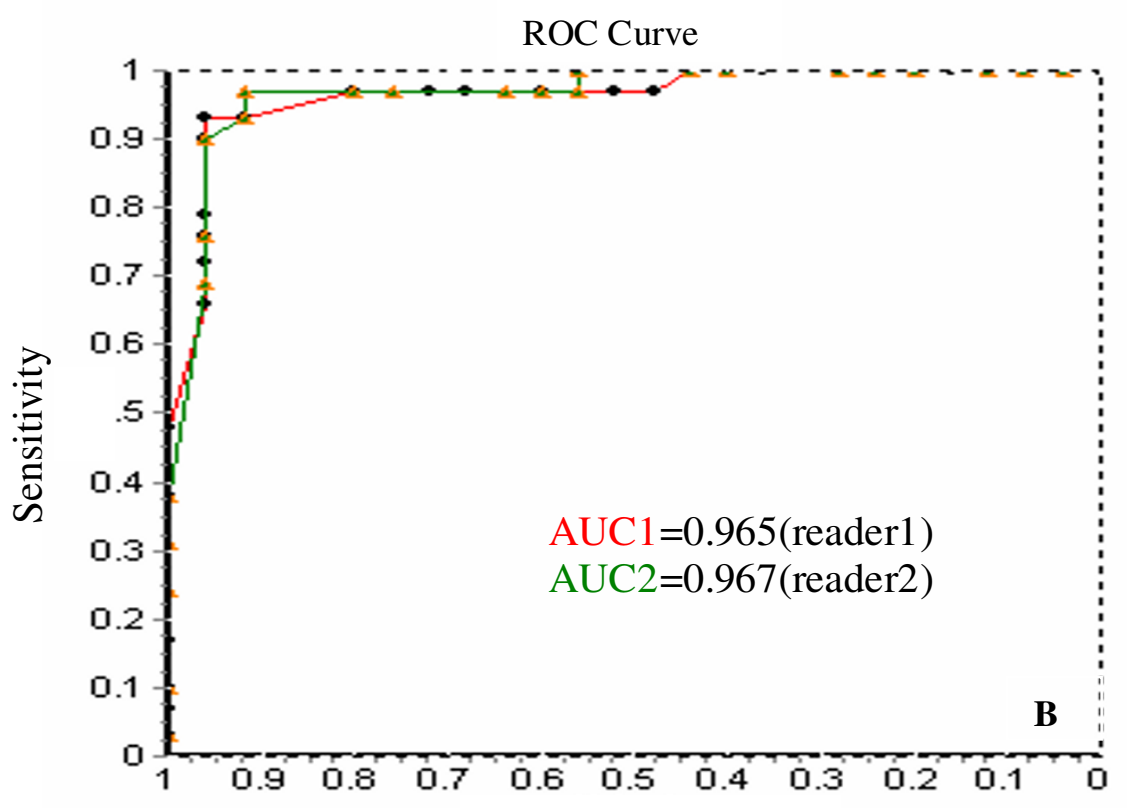

Specificity

\section{Figure 3}

$A:$ ROC curves for the ADC values from reader I and reader2 $(b=500)$. The area under the ROC curve (AUC) is $\mathbf{0 . 9 6 9}$ (reader $\mathrm{I}$ ) and $\mathbf{0 . 9 6 9}$ (reader 2$)$. B: ROC curves for the ADC values from reader I and reader $2(\mathrm{~b}=1000)$. The area under the ROC curve (AUC) is 0.965 (reader I) and 0.967 (reader2). 
Table 3: The summary of ROC curve

\begin{tabular}{lcccccc}
\hline & \multicolumn{2}{c}{ Readerl } & \multicolumn{2}{c}{ Reader2 } & & Average of both readers \\
\cline { 2 - 7 } & $b=500$ & $b=1000$ & $b=500$ & $b=1000$ & $b=500$ & $b=1000$ \\
\hline Threshold $\left(\times 10^{-3} \mathrm{~mm}^{2} / \mathrm{s}\right)$ & $1.29 \pm 0.25$ & $1.22 \pm 0.25$ & $1.39 \pm 0.25$ & $1.38 \pm 0.25$ & $1.24 \pm 0.25$ & $1.20 \pm 0.25$ \\
\hline Sensitivity & $93 \%$ & $93 \%$ & $93 \%$ & $97 \%$ & $93 \%$ & $96 \%$ \\
\hline Specificity & $91 \%$ & $96 \%$ & $96 \%$ & $92 \%$ & $100 \%$ & $97 \%$ \\
\hline
\end{tabular}

$\mathrm{mm}$, from the anatomic border of malignant tumor outwards, ADC value of each ROI layer with a thickness of 5 $\mathrm{mm}$ was measured till skin or until the ADC values of adjacent layers were very close to each other. The outermost layer in this study was layer 4 .

Our results showed that the ADC of malignant lesions was statistically lower than that of peri-tumor tissues (from layer 1 to layer 4$)$ in all directions (Figure 5$)(P<0.05)$, while there was no statistical difference in ADC values among the four directions within same layer.

Further detailed analysis showed that from layer 1 to layer 4 , the ADC value increased gradually (Figure 6). The ADC value of tumor lesion was significantly lower than that of each layer of peri-tumor tissues, while the ADC value of layer 1 was significantly lower than that of layer $2(P<$ 0.05). However, there was no significant difference between the ADC values of layer 2 and layer 3, or layer 3 and layer 4. Moreover, we also compared the ADC values of different layers with the normal contralateral breast tissue. We found that only ADC value of layer 1 was significantly lower than that of contralateral breast tissue $(P<$ 0.05).

\section{Discussion}

Despite the improvement in the detection of breast cancer with the widespread application of mammography and ultrasound, breast lesions still remain difficult to diagnose and characterize, especially in dense fibroglandular breasts. The main advantage of MRI in the breast is that they can improve the detection and characterization of multiple and/or small lesions even in the dense fibroglandular breasts. However, the low specificity of MRI remains a problem [20].

In recent years, the DWI has been extensively applied in evaluating cerebral tumors and the correlation between the ADC value and the cellular density has been verified. Briefly, the higher the cellular density is, the lower the $A D C$ value will be in DWI, and vice versa [21]. For malignant tumors, they have a relatively high cellular density and therefore will produce a low ADC value in DWI, while for benign lesion, its density is generally low and thus will produce a high ADC value in DWI. Application of DWI in the diagnosis of breast lesions has been reported recently $[14,16,22-24]$. These studies showed that in malignant breast tumors, the ADC was significantly lower than that in benign tumors. These authors concluded that ADC might help to differentiate benign and malignant lesions with good specificity, and may increase the overall specificity of breast MRI, which is consistent with our results.

In ROC curves, the specificity of the ADC is dependent on the threshold value that determines the differentiation between benign and malignant tumors. In our study, we

Table 4: Values of ADC measured in breast lesions

\begin{tabular}{cccc}
\hline Histology & No. & $\begin{array}{c}A D C(\text { range }) \times 10^{-3} \mathrm{~mm}^{2} / \mathrm{s} \\
b=500\end{array}$ & $\begin{array}{c}A D C(\mathrm{range}) \times 10^{-3} \mathrm{~mm}^{2} / \mathrm{s} \\
b=1000\end{array}$ \\
\hline Malignant lesions & 35 & $1.04 \pm 0.23^{\mathrm{a}}$ & $1.01 \pm 0.20^{\mathrm{b}}$ \\
\hline ductal carcinoma in situ & 3 & $0.99 \pm 0.18$ & $0.97 \pm 0.21$ \\
\hline infiltrating ductal carcinoma & 31 & $1.04 \pm 0.26$ & $1.02 \pm 0.19$ \\
\hline Sarcoma & 1 & $1.72 \pm 0.21$ & $1.72 \pm 0.13$ \\
\hline Benign lesions & 22 & $1.79 \pm 0.29$ & $1.73 \pm 0.34$ \\
\hline
\end{tabular}

aP $=0.000$, vs benign lesions; ${ }^{b} P=0.000$, vs benign lesions. 


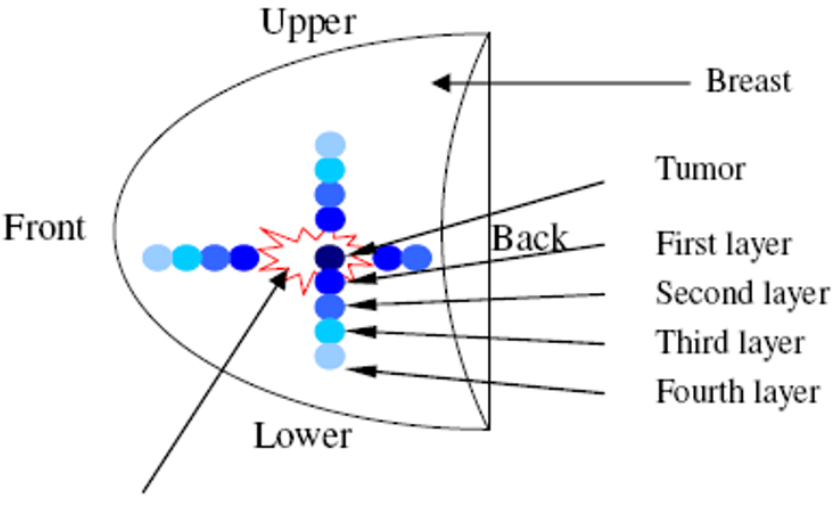

Breast cancer

\section{Figure 4}

This sagittal schematic drawing showed how we measured the ADC values of tumor tissue and peritumor tissues. The red crooked line presented the breast tumor and the small circles of different colors from dark blue to light blue presented different layers of peri-tumor tissues with a diameter of $5 \mathrm{~mm}$.

obtained two threshold values: $1.24 \pm 0.25 \times 10^{-3} \mathrm{~mm}^{2} / \mathrm{s}$ ( $b=500$ ) with $93 \%$ sensitivity and $100 \%$ specificity; and $1.20 \pm 0.25 \times 10^{-3} \mathrm{~mm}^{2} / \mathrm{s}(\mathrm{b}=1000)$ with $96 \%$ sensitivity and $97 \%$ specificity. The threshold of ADC value in our study was close to the data reported by Luo JD [16] (1.22 $\left.\times 10^{-3} \mathrm{~mm}^{2} / \mathrm{s}\right)$ and Rubesova E [14] (1.13 $\pm 0.10 \times 10^{-}$ ${ }^{3} \mathrm{~mm}^{2} / \mathrm{s}$ ). The reason of difference was that in our study we chose $b=500$ and $b=1000$ while in Luo JD's study, $b$ $=0$ and $\mathrm{b}=800$ and in Rubesova E's study, three-dimensional fast low-angle shot (3D-FLASH) with contrast injection was applied. An exception in our study is that one breast malignant phyllode had a high $\mathrm{ADC}$ value $(\mathrm{b}=$ $500,1.72 \pm 0.14 \times 10^{-3} \mathrm{~mm}^{2} / \mathrm{s} ; \mathrm{b}=1000,1.73 \pm 0.14 \times 10$

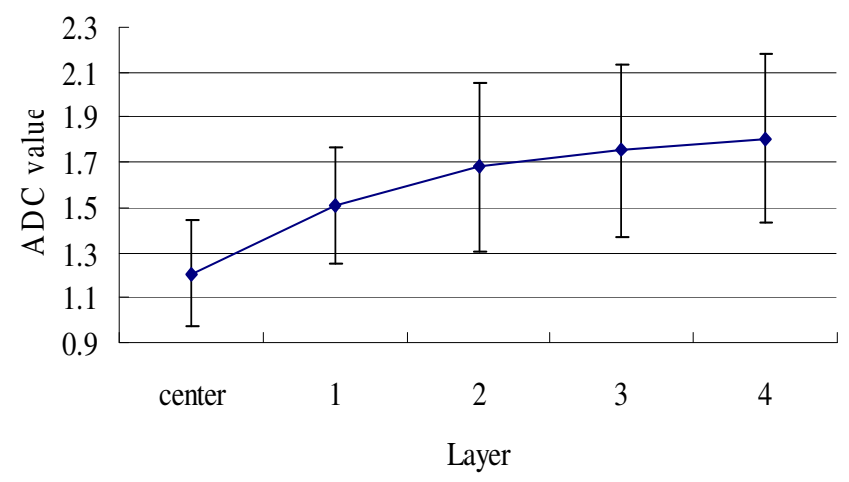

\section{Figure 5}

The ADC values $\left(\times 10^{-3} \mathrm{~mm}^{2} / \mathrm{s}\right)$ of tumor tissue and peri-tumor tissues in different directions. The standard deviation $\left(\times 10^{-3} \mathrm{~mm}^{2} / \mathrm{s}\right)$ was as following: front: 0.418 , back: 0.509, upper: 0.289 , blow: 0.374 , central: 0.155 .

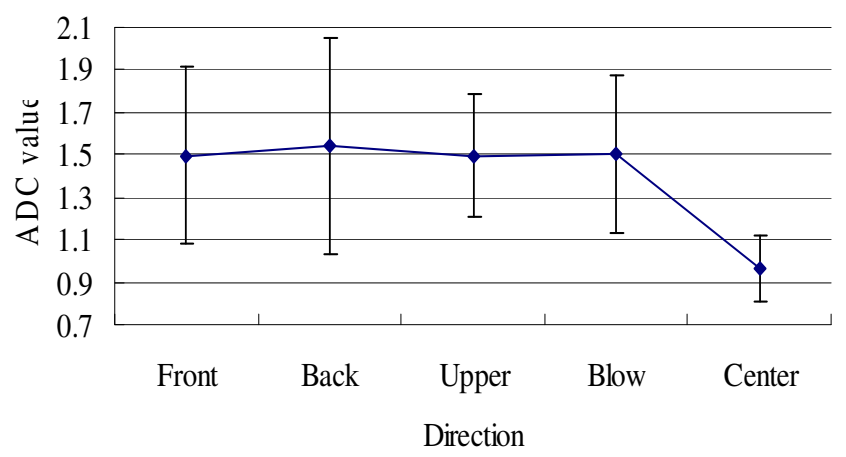

Figure 6

The ADC values $\left(\times 10^{-3} \mathrm{~mm}^{2} / \mathrm{s}\right)$ of tumor tissue and peri-tumor tissues of different layers. The standard deviation $\left(\times 10^{-3} \mathrm{~mm}^{2} / \mathrm{s}\right)$ was as following: tumor: 0.233 , first layer: 0.257 , second layer: 0.370 , third layer: 0.382 , fourth layer: 0.370 .

${ }^{3} \mathrm{~mm}^{2} / \mathrm{s}$ ), which was similar to that in Woodhams R's report $\left(1.67 \pm 0.59 \times 10^{-3} \mathrm{~mm}^{2} / \mathrm{s}\right)[12]$. The reason of a high ADC in tumor was that in this case the lesion was mainly liposarcoma histologically and the liposarcoma, similar to adipose tissue, has a relatively high ADC value.

Another important aim in our study is try to study the DWI changes in tissues adjacent to breast carcinoma. It is well known that over the past 30 years in the field of breast carcinoma surgery, the extent of surgery has been progressively reduced, which leads to less disfigurement and a significant improvement in life quality of patients [25]. From an oncological perspective, outcome of conservative breast surgery was found to be equally effective when compared with mastectomy [26]. However, tumor recurrence after breast-conserving surgery still remains a problem [27]. Many studies [28-31] reported that obtaining negative surgical margins in conservative breast surgery influenced the incidence of local disease recurrence and probably overall survival. Preoperative evaluation of the change in peri-tumor tissue will plays an important role for the success of conservative operation.

Nowadays in clinical works, the preoperative estimation of the excision scope of breast tumor is generally made by surgeon according to his own experience, based on the results of mammography, ultrasound and conventional MRI. However, because the capacity for malignant growth is acquired by the stepwise accumulation of defects in specific genes regulating cell growth and tissue homeostasis [32], the genetic and molecular alteration prior to phenotypic changes in peri-tumor tissues usually could not be reflected by conventional mammography, ultrasound and MRI examinations. On the other hand, although intraoperative pathological diagnosis was regarded as an impor- 
tant standard second only to routine paraffin section for the evaluation of negative or positive margin of tumor, it can only be performed approximately 30 minutes post excision of the lesion and the decision must be made intraoperatively [33-37]. Routine paraffin section diagnosis is the "gold standard", however, the data will be decided after operation a couple of days. Therefore, it is essential to explore new techniques that should be noninvasive and could detect the change of peri-tumor tissue before operation. For these reasons, DWI, due to its distinct characteristics mentioned above, might provide some information on the microstructure change of breast tissues and probably becomes a potentially valuable method for evaluating the change of peri-tumor tissue in breast carcinoma.

In our present study we first applied DWI to compare the $A D C$ value of malignant tumor with that of its peripheral tissue. We found that from the parenchyma of tumor to its peripheral tissue, which was layered with a thickness of 5 $\mathrm{mm}$, the ADC values gradually increased and between the innermost layer 1 and other outer layers, there was a significant difference in their ADC values $(P<0.05)$, while there was no difference from layer 2 to layer 4 . Further comparison study showed that only ADC value of layer 1 was significantly lower than that of normal contralateral breast tissue. Although from layer 2 outwards, there was no statistical difference among different layers, it can not be concluded that the tissue in layer 2 , or even outer layers, was completely normal, since the tumor intrude into surrounding tissue with infiltrative growth pattern but we considered each layer as a homogeneous tissue while we performed statistical analysis.

Besides, since this work was basically a methodological study and our aim was to study the change of ADC values change in peri-tumor tissue by the novel MRI technique, all the lesions recruited in our study were from mastectomy and relatively large in size. Therefore, further researches are needed to assess whether the results and threshold in the present study could be also applied to the smaller lesions.

\section{Conclusion}

In conclusion, our study showed that the ADC value was a sensitive and specific parameter that can help to differentiate benign and malignant breast lesions with a threshold value of $1.24 \pm 0.25 \pm 10^{-3} \mathrm{~mm}^{2} / \mathrm{s}(\mathrm{b}=500)$ and 1.20 $\pm 0.25 \pm 10^{-3} \mathrm{~mm}^{2} / \mathrm{s}(\mathrm{b}=1000)$. Our results also showed that the ADC values increased gradually from the tumor to peri-tumor to normal tissues and there existed a region with a thickness of about $5 \mathrm{~mm}$ surrounding the border of tumor (by routine MRI), which has an abnormal ADC value, while beyond this region, the ADC value of tissue return to a normal range gradually.
Our next stage studies will include: 1) Measure ADC value of each ROI layer with a thinner thickness to detect the gradual change from carcinoma to normal tissue; 2 ) Compare the examination of DWI with that of pathological histology about the change of peri-tumor tissue in breast carcinoma and study the correlation of diagnosis between these two methods.

\section{Abbreviations}

ADC: Apparent Diffusion Coefficient; DWI: DiffusionWeighted Imaging; MRI: Magnetic Resonance Imaging; ROC: Receiver Operating Characteristic; ROI: Region Of Interest.

\section{Competing interests}

The authors declare that they have no competing interests.

\section{Authors' contributions}

YLZ conceived of the study concept and participated in its design, MRI imaging data acquisition, literature research, statistical analysis, manuscript drafting and editing, approval for important intellectual concepts. XYH carried out the MRI imaging data acquisition, participated in the literature research and manuscript drafting and editing. HWD participated in the clinical study, imaging data analysis and manuscript drafting and editing. YZ participated in the clinical study, imaging data analysis, literature research. XC participated in the clinical study, data acquisition, statistical analysis. PW participated in the clinical study, data acquisition, literature research and statistical analysis. YMG conceived the study concept and participated in design, manuscript drafting and editing data analysis and interpretation, approval for important intellectual concepts. All authors read and approved the final manuscript.

\section{Acknowledgements}

This study was supported by: National Natural Science Foundation of China (No.6050 1 006) and Science and technology Foundation of Shaanxi Province of China (No. 2006K09-G(2)). Written consent for publication was obtained from the patients.

\section{References}

I. Masetti R, Di Leone A, Franceschini G, Magno S, Terribile D, Fabbri $M C$, Chiesa F: Oncoplastic techniques in the conservative surgical treatment of breast cancer: an overview. Breast J 2006: 174-80.

2. Choi Seungtaek, Thames Howard D, Buchholz Thomas A: Integration of Radiation Therapy and Systemic Therapy for Breast Cancer. Springer Berlin Heidelberg 2006:25I-265.

3. Goldenberg David, Harden Susan, Masayesva Brett G, Ha Patrick, Benoit Nicole, Westra William H, Koch Wayne M, Sidransky David, Califano Joseph A: Intraoperative Molecular Margin Analysis in Head and Neck Cancer. Arch Otolaryngol Head Neck Surg 2004, 130:39-44.

4. Yan Pearlly S, Venkataramu Chinnambally, Ibrahim Ashraf, Liu Joseph C, Shen Rulong Z, Diaz Nils M, Centeno Barbara, Weber Frank, YuWei Leu, Shapiro Charles L, et al.: Mapping Geographic Zones of Cancer Risk with Epigenetic Biomarkers in Normal Breast Tissue. Clinical Cancer Research 2006, I 2(22):6626-6636. 
5. Kim J, Reber HA, Dry SM, Elashoff D, Chen SL, Umetani N, Kitago M, Hines OJ, Kazanjian KK, Hiramatsu S, et al.: Unfavourable prognosis associated with K-ras gene mutation in pancreatic cancer surgical margins. Gut 2006, 55(I I): |598-605.

6. Masasyesval Brett G, Tong Betty C, Brock Malcolm V, Pilkington Thomas, Goldenberg David, Sidransky David, Harden Susan, Westra William H, Califano Joseph: Molecular margin analysis predicts local recurrence after sublobar resection of lung cancer. International journal of cancer 2005, I I 3(6): I 022-I025.

7. Zhang Dingdong, Bai Yunfei, Ge Qinyu, Qiao Yingjuan, Wang Yan, Chen Zaozao, Lu Zuhong: Microarray-based molecular margin methylation pattern analysis in colorectal carcinoma. Analytical biochemistry 2006, 355(I): I I7-24.

8. Pan Zhi-Zhong, Wan De-Sen, Zhang Chang-Qing, Shao Jian-Yong, Li Li-Ren, Chen Gong, Zhou Zhi-Wei, Wang Fu-Long: Using p53immunostained large specimens to determine the distal intramural spread margin of rectal cancer. World J Gastroenterol 2006, I 2(10): 1626-1629.

9. Yang Bin, Gao Ying-Tang, Du Zhi, Zhao Lei, Song Wen-Qin: Methylation-based molecular margin analysis in hepatocellular carcinoma. Biochemical and Biophysical Research Communications 2005, 338(3): I 353-I 358.

10. Manenti G, Squillaci E, Di Roma M, Carlani M, Mancino S, Simonetti $G$ : In vivo measurement of the apparent diffusion coefficient in normal and malignant prostatic tissue using thin-slice echo-planar imaging. Radiol Med (Torino) 2006, I I I (8): I I 24-33.

I I. Koyama T, Togashi K: Functional MR imaging of the female pelvis. Journal of magnetic resonance imaging 2007, 25(6): I I0 I-I2

12. Woodhams R, Matsunaga K, Kan S, Hata H, Ozaki M, Iwabuchi K Kuranami M, Watanabe M, Hayakawa K: ADC mapping of benign and malignant breast tumors. Magnetic resonance in medical sciences 2005, 4(I):35-42.

13. Hartmann M, Junkers R, Herold-Mende C, Ahmadi R, Heiland S: Pseudonormalization of diffusion weighted images: magnetic resonance imaging in an animal model (C6-glioma). Rofo 2005, I77(I): II4-8.

14. Rubesova E, Grell AS, De Maertelaer V, Metens T, Chao SL, Lemort M: Quantitative Diffusion Imaging in Breast Cancer: A Clinical Prospective Study. Journal of magnetic resonance imaging 2006, 24:319-324.

15. Kim CK, Park BK, Han JJ, Kang TW, Lee HM: Diffusion-weighted imaging of the prostate at $3 \mathrm{~T}$ for differentiation of malignant and benign tissue in transition and peripheral zones: preliminary results. Journal of Comput Assist Tomogr 2007 3 I(3):449-54.

16. Luo JD, Liu YY, Zhang XL, Shi LC: Application of diffusion weighted magnetic resonance imaging to differential diagnosis of breast diseases. Ai Zheng 2007, 26(2): I68-7|

17. Woodhams R, Matsunaga K, Iwabuchi K, Kan S, Hata H, Kuranami M, Watanabe M, Hayakawa K: Diffusion-weighted imaging of malignant breast tumors: the usefulness of apparent diffusion coefficient (ADC) value and ADC map for the detection of malignant breast tumors and evaluation of cancer extension. Journal of Comput Assist Tomogr 2005, 29(5):644-9.

18. Kuroki Y, Nasu K, Kuroki S, Murakami K, Hayashi T, Sekiguchi R, Nawano S: Diffusion-weighted imaging of breast cancer with the sensitivity encoding technique: analysis of the apparent diffusion coefficient value. Magn Reson Med Sci 2004, 3(2):79-85.

19. Pickles MD, Gibbs P, Lowry M, Turnbull LW: Diffusion changes precede size reduction in neoadjuvant treatment of breast cancer. Magn Reson Imaging 2006, 24(7):843-7.

20. Kuhl CK: Concepts for differential diagnosis in breast MR imaging. Magn Reson Imaging Clin N Am 2006, I 4(3):305-28.

21. Rumpel H, Khoo JB, Chang HM, Lim WE, Chen C, Wong MC, Tan KP: Correlation of the apparent diffusion coefficient and the creatine level in early ischemic stroke: a comparison of different patterns by magnetic resonance. Journal of magnetic resonance imaging 2001, I 3(3):335-43.

22. Kuroki Y, Nawano S, Hasebe T, Imoto S, Nasu K, Murakami K, Satake M, Sekiguchi R, Hayashi T: Efficacy of MR mammography (MRM) in providing preoperative locoregional information on breast cancer: correlation between MRM and histological findings. Magnetic resonance in medical sciences 2002, I(2):73-80.

23. Guo Y, Cai YQ, Cai ZL, Gao YG, An NY, Ma L, Mahankali S, Gao JH: Differentiation of clinically benign and malignant breast lesions using diffusion-weighted imaging. Journal of magnetic resonance imaging 2002, 16(2): 172-8.

24. Luini A, Gatti G, Galimberti V, Zurrida S, Intra M, Gentilini O, Paganelli G, Viale G, Orecchia R, Veronesi P: Conservative treatment of breast cancer: its evolution. Breast cancer research and treatment 2005, 94(3): 195-8.

25. Cocquyt VF, Blondeel PN, Depypere HT, Sijpe KA Van De, Daems KK, Monstrey SJ, Van Belle SJ: Better cosmetic results and comparable quality of life after skin-sparing mastectomy and immediate autologous breast reconstruction compared to breast conservative treatment. British journal of plastic surgery 2003, 56(5):462-70.

26. Meric F, Mirza NQ, Vlastos G, Buchholz TA, Kuerer HM, Babiera GV, Singletary SE, Ross MI, Ames FC, Feig BW, et al.: Positive surgical margins and ipsilateral breast tumor recurrence predict disease-specific survival after breast-conserving therapy. Cancer 2003, 97(4):926-33.

27. Horst KC, Smitt MC, Goffinet DR, Carlson RW: Predictors of local recurrence after breast-conservation therapy. Clinical breast cancer 2005, 5(6):425-38.

28. Kuerer HM, Arthur DW, Haffty BG: Repeat breast-conserving surgery for in-breast local breast carcinoma recurrence: the potential role of partial breast irradiation. Cancer 2004, 100(II):2269-80.

29. Fatouros M, Roukos DH, Arampatzis I, Sotiriadis A, Paraskevaidis E, Kappas AM: Factors increasing local recurrence in breast-conserving surgery. Expert Rev Anticancer Ther 2005, 5(4):737-45.

30. Kunos C, Latson L, Overmoyer B, Silverman P, Shenk R, Kinsella T, Lyons J: Breast conservation surgery achieving $>$ or $=2 \mathrm{~mm}$ tumor-free margins results in decreased local-regional recurrence rates. Breast 2006, I 2(I):28-36.

31. Berg WA, Gutierrez L, NessAiver MS, Carter WB, Bhargavan M, Lewis RS, loffe OB: Diagnostic accuracy of mammography, clinical examination, US, and MR imaging in preoperative assessment of breast cancer. Radiology 2004, 233(3):830-49.

32. Sidransky D, Hollstein M: Clinical implications of the p53 gene. Annu Rev Med 1996, 47:285-30I.

33. Balch GC, Mithani SK, Simpson JF, Kelley MC: Accuracy of intraoperative gross examination of surgical margin status in women undergoing partial mastectomy for breast malignancy. Am Surg 2005, 7 I (I):22-7.

34. Clarke GM, Eidt S, Sun L, Mawdsley G, Zubovits JT, Yaffe MJ: Wholespecimen histopathology: a method to produce wholemount breast serial sections for 3-D digital histopathology imaging. Histopathology 2007, 50(2):232-42.

35. Obrist P, Brunhuber T, Ensinger C, Zelger BG, Dünser M, Buchberger W: Pathological examination of breast biopsy specimens. Radiologe 2002, 42(I): I-5.

36. Rubio IT, Marco V: The importance of surgical margins in conservative surgery for breast cancer. Cirugía española 2006, 79(1):3-9.

37. Silverstein MJ: An argument against routine use of radiotherapy for ductal carcinoma in situ. Oncology (Williston Park) 2003 I7(II): $1511-33$.

\section{Pre-publication history}

The pre-publication history for this paper can be accessed here:

http://www.biomedcentral.com/1471-2407/9/18/prepub 